\begin{tabular}{|l|l|l|l|l|l|}
\hline MUNIBE Antropologia-Arkeologia & $n^{\circ} 72$ & $71-83$ & DONOSTIA & 2021 & ISSN 1132-2217 • eISSN 2172-4555 \\
\hline
\end{tabular}

\title{
Bovinos en estructuras funerarias del Neolítico Medio del noreste de la Península Ibérica. La necrópolis de la Bòbila Madurell como caso de estudio sobre la gestión del vacuno
}

\author{
Cattle in Middle Neolithic burials of eastern Iberia. \\ The Bòbila necropolis as a case study on cattle management
}

PALABRAS CLAVES: Arqueozoología, reconstrucción de los rebaños, osteometría, perfiles de edad de muerte GAKO-HITZAK: Arkeozoologia, azienden berreraiketa, osteometria, heriotza-adinaren profilak.

KEY WORDS: Zooarchaeology, herds composition, osteometry, age-at-death profiles.

Silvia ALBIZURII ${ }^{(1)}$, Araceli MARTíN CólLIGA ${ }^{(2)}$, Juan F. GIBAJA ${ }^{(3)}$, Patricia MARTíN ${ }^{(1,4,5) \star}$

\section{RESUMEN}

En la ganadería neolítica de la Península Ibérica el bovino doméstico (Bos taurus) fue el segundo taxón en importancia, después de los ovicaprinos. Algunos yacimientos constituyen una excepción y presentan una mayor abundancia de bovino. Éste es el caso de la necrópolis de la Bòbila Madurell (4210-3670 cal BC), la más extensa del Neolítico Medio peninsular en superficie y en número de tumbas.

El objetivo de este trabajo es estudiar la configuración de la cabaña bovina a partir de los conjuntos faunísticos registrados en los principales sectores de la necrópolis. Un volumen de restos importante ha permitido diferenciar 37 animales en 20 estructuras. Basándonos en el análisis osteométrico se caracteriza el conjunto y se descarta la presencia de ejemplares salvajes o uros (Bos primigenius).

Los resultados indican que el rebaño fue explotado básicamente para la obtención de carne una vez obtenido su peso óptimo y secundariamente para el aprovechamiento de la leche.

\section{LABURPENA}

Iberiar penintsulako abeltzaintza neolitikoan, eta ardiak ondoren, garrantziari dagokionez bigarren taxona etxeko behi-azienda (Bos taurus) izan zen. Aztarnategi batean, salbuespena dira eta behin-azienden kopurua ugariagoa da. Horixe bera gertatzen da Bòbila Madurelleko nekropoliaren kasuan (K.a. 4210-3670 gutxi gorabehera). Azalerari eta hilobi kopuruari dagokienez, Iberiar penintsulako Erdiko Neolitoko handiena da.

Lan honen helburua da nekropoliko sektore nagusietan erregistratutako multzo faunistikoetatik abiatuta behi-aziendaren konfigurazioa aztertzea. Aztarnen bolumena handia denez, 20 egituratan 37 animalia bereizi ditugu. Azterketa osteometrikoan oinarrituta, multzoa karakterizatu eta uroen (Bos primigenius) edo ale basatien presentzia baztertu dugu.

Emaitzek agerian utzi dute azienda haragia lortzeko ustiatu zutela batez ere haien pisu egokia lortutakoan, eta bigarren mailan, aldiz, esnea aprobetxatzeko.

\section{ABSTRACT}

Cattle was one of the main species raised by the first Neolithic farmers in the Iberian Peninsula. In most of the sites, domestic Caprines were the basis of the economy, with cattle being a complement. However, there were some exceptions, especially in open-air settlements, where bovines were the main species bred. This is the case of the necropolis of Bòbila Madurell (4210-3670 cal BC), the most extensive of the Iberian Middle Neolithic in surface and number of tombs. The importance of the cattle in the ritual of this site has been related to its economic importance for these groups of the Middle Neolithic.

This work focuses on the zooarcheological study of cattle remains recovered in the two main sectors of this necropolis, "Madurell Sud" and "Madurell Ferrocarrils". The aim is to analyse the management of cattle herds during the Middle Neolithic.

The osteometric analyses and the determination of the age-at-death and obtaining mortality profiles have been the basis of this study. Osteometric analysis has made it possible to differentiate between the remains of cattle and their agriotype, the aurochs. Mortality profiles provide information on the economic use of these animals. 37 individuals were identified from 20 structures.

Based on the osteometric analysis, we have characterized the whole and ruled out the presence of wild specimens or aurochs (Bos primigenius). Mortality profiles indicate that the herd was exploited basically for meat, once its optimum weight was obtained, and secondarily for milk.

\footnotetext{
*Corresponding autor. E-mail address: patrimr9@gmail.com. Phone: (+34) 977943003.

(1) SERP, Departament d'Història i Arqueologia, Universitat de Barcelona, Montealegre 6-8, 08001, Barcelona. silvia.albizuri@upc.edu

(2) Servei d'Arqueologia i Paleontologia de la Generalitat de Catalunya. amcolliga@yahoo.es

(3) Escuela Española de Historia y Arqueología en Roma (EEHAR-CSIC). Via di Sant'Eufemia 13, 00187, Rome (Italy), juan.gibaja@eehar.csic.es

(4) Institut de Paleoecologia Humana i Evolució Social (IPHES-CERCA), Zona educacional 4, Campus Sescelades URV (Edifici W3), 43007, Tarragona.

(5) Universitat Rovira i Virgili (URV), Departament d'Història i Història de l'Art. Avinguda de Catalunya 35, 43002, Tarragona.
} 


\section{INTRODUCCIÓN}

Desde su introducción en la Península Ibérica, durante la segunda mitad del VI milenio cal $\mathrm{BC}$, el bovino doméstico fue utilizado como fuente de alimentos (carne y leche) así como por su fuerza para la tracción y el arado, como indican algunos yacimientos del noreste (Tarrús et al., 2006) y, probablemente, también para el abonado de las tierras.

El noreste es una de las áreas donde se documentan evidencias más antiguas de la llegada de los animales domésticos a la Península Ibérica (Saña et al., 2020). En esta zona, durante todo el período neolítico, se desarrolló una economía mixta, agrícola y ganadera, que combinaba el cultivo de cereales y leguminosas con la cría de ovejas y cabras, vacas y, en menor medida, de cerdos. Los ovicaprinos suelen ser la especie mejor representada a lo largo de todo el Neolítico, aunque, en algunos yacimientos, los bovinos son la especie predominante, especialmente en los ubicados al aire libre (Saña, 1998; Saña, 2013). Lo mismo ocurre en el área cantábrica y en la Meseta Norte, destacando una alta presencia general de ovicaprinos en los abrigos y cuevas (Altuna y Mariezcurrena, 2009).

Estos sistemas de cría mixta de diferentes especies domésticas habrían permitido optimizar la obtención de carne y subproductos, así como el aprovechamiento del entorno de cara a su alimentación, como se ha mostrado en un reciente estudio centrado en los niveles del Neolítico antiguo del poblado de La Draga (Girona) (Navarrete et al., 2019). En este asentamiento los ovicaprinos y los bovinos domésticos fueron alimentados con estrategias variables de forraje (hierba o heno y granos o subproductos de procesamiento de cultivos). Las ovejas se alimentaron de la vegetación más variada del entorno que comprendía zonas de pantanos y espacios forestales. Esto evidencia el alto grado de adaptación alimentario de ovejas y cabras, mientras que las vacas se alimentaron en áreas de pastizal con un aporte de forraje en épocas específicas.

En general, el modelo agrícola cerealístico del Neolítico, en el noreste peninsular, contribuyó a la explotación de las áreas circundantes a los asentamientos. El bovino se pudo adaptar bien a estos terrenos en los que se combinarían zonas de cultivo y pastos. La morfología de la boca de estos animales permite cortar la hierba a menor altura que las ovejas, aprovechando mucho mejor el pasto y favoreciendo su regeneración de una forma sostenible (Claro, 2018). Probablemente, esta adaptación fue uno de los factores que influyó en una creciente importancia del bovino en el transcurso del Neolítico.

En paralelo a esta estructuración económica agroganadera, las comunidades del Neolítico medio I (4500-4200 BC) y II (4200-3500 BC) del noreste peninsular, desarrollaron una cultura funeraria que, sin duda, refleja una estandarización en torno al tratamiento de la muerte. La denominada "Cultura de los Sepulcros de
Fosa" cristalizó a finales del V milenio en la fase II. Ésta se caracteriza por inhumaciones en fosas individuales y posiciones cuidadas de los cuerpos, con variaciones arquitectónicas según el territorio. En el grupo Vallesià, cuyo yacimiento más paradigmático es la necrópolis de Bóbila Madurell (Sant Quirze del Vallès, Barcelona), se identifican también algunos casos de inhumación doble y múltiple (Martín Cólliga et al., 2017; Plasencia, 2016), incluso las inhumaciones en silo o contenedor funerario caracterizadas por las posiciones descuidadas de los cuerpos o aparición de restos humanos desarticulados o aislados (Martín Cólliga et al., 2017).

Los ajuares compuestos por diferentes elementos (cerámicas, herramientas y adornos) se acompañaron, en algunas ocasiones, de restos de origen animal, aunque normalmente eran muy escasos. Sin embargo, también se han documentado excepciones. Uno de los ejemplos más destacables, es el importante volumen registrado en algunos contenedores funerarios de la Bòbila Madurell, que incluyen bovinos y perros enteros, en ocasiones, en conexión anatómica. Un reciente estudio llevado a cabo en dos de los sectores, Madurell Sud y Madurell Ferrocarrils, ha puesto de manifiesto la importancia simbólica de los animales para estas comunidades (Martín et al., 2019), especialmente de los animales domésticos por su predominio ante las especies salvajes. En concreto, la importancia de los bovinos se documenta a través de varias evidencias:

1)es la especie con un número mínimo de individuos (NMI) más elevado,

2)es la especie representada en un mayor número de tumbas,

3)es la especie que manifiesta una mayor diversidad en la forma de representación en las tumbas (conexiones anatómicas completas y/o parciales, restos fragmentados con marcas de procesamiento y consumo y elementos anatómicos aislados especialmente identificativos).

Estos tres factores, permitieron plantear que el bovino podría haber tenido tanto un papel simbólico, a modo de ofrendas, como en la celebración de posibles festines funerarios (Martín et al., 2019). Ovejas, cabras y cerdos, también pudieron haber desempeñado este rol, pero con niveles más bajos de representación que las vacas. En el caso de los perros, se manifiesta una clara asociación con los depósitos de vaca y con los inhumados. Los estudios isotópicos muestran que estos perros tuvieron una dieta mixta, muy similar a la humana, evidenciando la estrecha relación entre unos y otros, y el posible uso del perro como animal de trabajo (Albizuri et al., 2019).

Pese a la importancia manifiesta del bovino para las sociedades del Neolítico en la Península Ibérica $y$, en concreto, en el nordeste peninsular, el estudio zooarqueológico de esta cabaña ganadera, ha sido complejo debido a varios factores: 1) los restos no son abundantes en la mayoría de los yacimientos y suelen 
aparecer muy fragmentados, 2) estos restos pueden confundirse con los de los uros, cazados todavía en algunos yacimientos neolíticos (Castaños, 1984; Nadal et al., 1999; Castaños, 2004; Altuna y Mariezkurrena, 2009; Saña, 2013).

En base a todo lo expuesto, y dada la relativa abundancia de ganado bovino en las sepulturas de la Bòbila Madurell, desarrollamos un estudio de estos restos óseos para realizar una caracterización de esta cabaña y aproximarnos al aprovechamiento económico de estos animales durante el Neolítico Medio. Para ello, se realiza un análisis osteométrico y un estudio de los perfiles de edad de sacrifico que ponen de manifiesto las pautas de gestión del rebaño.

\section{LA BÒBILA MADURELL}

El yacimiento se sitúa a escasos $20 \mathrm{Km}$ del litoral de Barcelona, en el corredor prelitoral dentro del Vallès Occidental (Fig. 1A). Se ha datado entre el 4210 and 3670 cal. BC (20) (Gibaja et al., 2017; Díaz Zorita et al., 2021). Con una extensión de 28 ha, se ubicó en llanuras fértiles bien irrigadas y comunicadas. Repartidas entre diferentes sectores (Fig.1B), se han excavado más de 130 sepulturas y decenas de fosas, la mayoría silos con residuos domésticos, aunque su número real debió ser muy superior si tenemos en cuenta que, posteriormente, fue ocupada desde el Calcolítico Veraza, y en la actualidad modificada por infraestructuras viarias y explotada para extracción de arcillas y cultivos. En su límite norte, a menos de 500 m del sector Mas Duran,
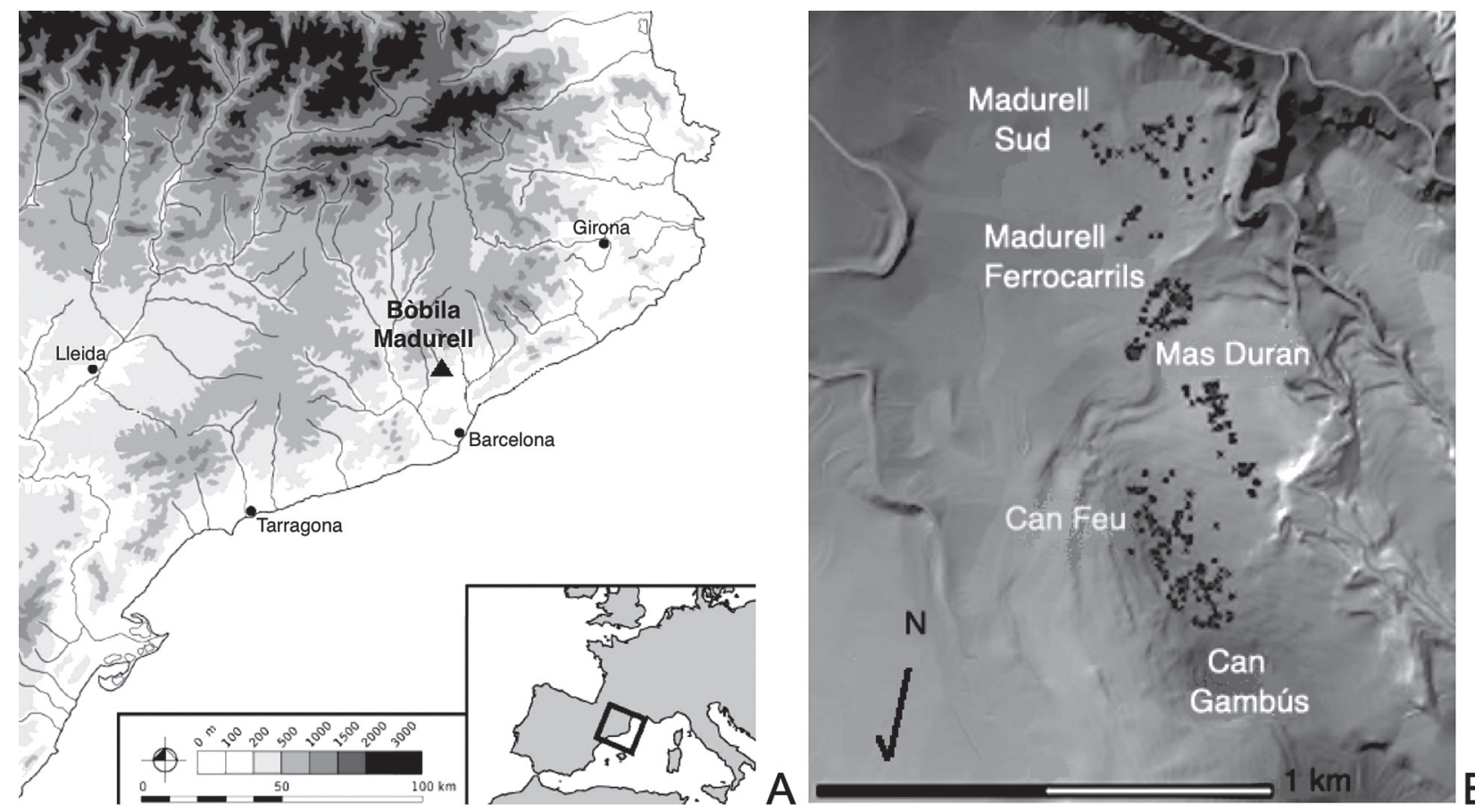

Fig.1. A situación de los yacimientos de Bòbila Madurell y Can Gambús I. B. Sectores arqueológicos del paraje Bòbila Madurell-Can Gambús. / A: Location of the Bòbila Madurell and Can Gambús I sites. B: Archaeological sectors of the Bòbila Madurell-Can Gambús site. 
Los restos faunísticos del interior de estructuras funerarias - sectores MS y MF- también muestran un alto porcentaje de los animales domésticos, que constituyen el 97\% del total identificado (Martín et al., 2019). Aunque, a diferencia de los considerados como restos de consumo ordinario, en las estructuras vinculadas con restos humanos, predomina el bovino sobre los ovicaprinos y los cerdos (según el NMI el bovino representa el $33.3 \%$, los ovicaprinos el $24.8 \%$ y los cerdos el 25.7\%) (Fig. 2).

La agricultura se encuentra constatada a través de los restos carpológicos. En la misma línea, las prácticas agrícolas quedan reflejadas por la aparición de herramientas relacionadas con el acondicionamiento de terrenos forestales, la recolecta y procesado, como son las hachas y azuelas, las hoces y los molinos. La agricultura se basó en el cultivo de cereales con predominio de la cebada y el trigo en combinación con las leguminosas (principalmente lentejas y guisantes). Fue complementada con la recolección de frutos. Se trataría de una agricultura intensiva cerealística para el autoconsumo y la siembra, explotando en barbecho la tierra (Antolín et al., 2015, Plasencia 2016). Por otro lado, los análisis isotópicos de la población de Bòbila Madurell muestran una dieta basada en vegetales del grupo C3. El componente proteico de la dieta consistió principalmente en carne, leche y otros productos lácteos del ganado (Fontanals-Coll et al., 2015).

\section{MATERIALES Y MÉTODOS}

Se han analizado 337 restos de bovino, pertenecientes a un mínimo de 37 ejemplares. Algunos de ellos están bien representados anatómicamente y recuperados en conexiones anatómicas parciales o completas, otros son fragmentos que aparecen dispersos en las estructuras. Todos ellos fueron recuperados en 19 estructuras con restos humanos de los sectores MS y MF y en una fosa doméstica tipo silo, la B12, a pocos metros del sector MF, y en cuyo entorno solo se registraron siete tumbas (Tabla 1). La anómala cantidad de materiales de la fosa B12 datada en 3945-3710 cal BC, incluyendo materiales exógenos y numerosos restos faunísticos (NRD=172), nos lleva a plantear que esta estructura sirvió como contenedor de los restos relacionados con una ceremonia fúnebre posiblemente asociada a alguna de las sepulturas anexas, destacando la contemporánea B10 datada en 3957-3795 cal BC.

El estudio osteométrico se ha realizado con el objetivo de diferenciar los ejemplares salvajes (uros o Bos primigenius) de los domésticos (Bos taurus). En principio, el uro se diferencia del bovino doméstico por sus grandes dimensiones, aunque su morfología ósea es muy similar. En su tamaño y robustez pueden confundirse las hembras salvajes con machos domésticos de gran talla y castrados. El análisis de la variabilidad morfométrica se ha realizado para caracterizar a los animales a partir de los elementos mejor conservados: astrágalos, metacarpos y falanges proximales.

Las medidas han sido tomadas con un calibre digital vernier según los criterios establecidos por von den Driesch (1976) y Davis y Sendim (2020).

Las medidas obtenidas en la Bòbila Madurell han sido comparadas con las de otros yacimientos del nordeste peninsular en un contexto cultural similar: Can Roqueta, a escasos kilómetros de la Bòbila Madurell (Terrats et al., en prensa), con Casserna de Sant Pau (Albizuri y Nadal, 1993), Pujolet de Moja y Pou Nou (Nadal et al., 1999), todos ellos en Barcelona, además de La Draga, en Girona, del Neolítico Antiguo Cardial (Helmer et al., 2018).

También han sido seleccionados conjuntos del Norte peninsular datados entre el Mesolítico y el Neolítico Final: Gibijo (Altuna, 1974; Laurino, 2006) y La Renke (Altuna y Mariezcurrena, 2001) en Álava, Arenaza en Vizcaya (Altuna, 1980), El Mirador en Burgos (Martín, 2015) y la Cueva de Chaves en Huesca (Castaños, 2004). Además, se añaden uros mesolíticos bien diferenciados sexualmente del suroeste en Portugal, dentro del estuario de del Sado y el Muge (Davis y Mataloto, 2012; Davis y Sendim, 2020).

Dentro del noreste peninsular se han utilizado datos de otros yacimientos cercanos a Bòbila Madurell

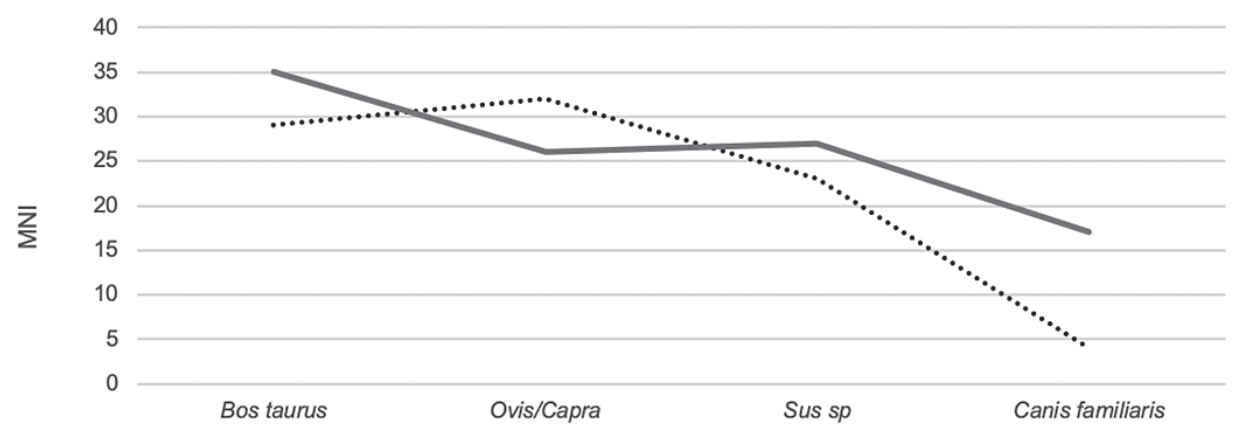

...... Mas Duran (fosas domésticas, $n=26$ )
Madurell S-Madurell F (fosas funerarias $n=20$ )
Fig.2. Representación de especies domésticas en estructuras funerarias y fosas domésticas del Neolítico Medio de la Bòbila Madurell, según el NMI. / Representation of domestic species in funerary structures and domestic graves of the Middle Neolithic of the Bòbila Madurell, according to the NMI. 


\begin{tabular}{|c|c|c|c|c|c|c|}
\hline Yacimiento & Estructura & $\begin{array}{l}\text { Período/Cronología } \\
\text { Cal BC } 2 \text { sigma }\end{array}$ & Tipología & $\begin{array}{c}\text { Humanos/sexo } \\
\text { (edad aprox. en años) }\end{array}$ & NMI Bos & NRD Bos \\
\hline B.Madurell Sud & MS1 & Neolítico Medio II & Fosa funeraria & 2 infantiles (c. 9 a) & 1 & 1 \\
\hline B.Madurell Sud & MS8 & Neolítico Medio II & Contenedor funerario & $1 \mathrm{AD} /$ macho & 1 & 1 \\
\hline B.Madurell Sud & MS9 & Neolítico Medio II & Contenedor funerario & $2 \mathrm{AD} /$ macho & 1 & 1 \\
\hline B.Madurell Sud & MS12 & Neolítico Medio II & Tumba & 1 SubAD (4 a) & 1 & 3 \\
\hline B.Madurell Sud & B12 & $3945-3710 \mathrm{cal} \mathrm{BC}$ & Fosa doméstica & & 2 & 89 \\
\hline B.Madurell Sud & MS15 & Neolítico Medio II & Tumba & 1 SubAD (4 a) & 1 & 1 \\
\hline B.Madurell Sud & MS16 & Neolítico Medio II & Tumba & 1 AD/hembra (30-40 a) & 1 & 1 \\
\hline B.Madurell Sud & MS17 & 3939-3681 cal BC & Contenedor funerario & 1 infantil (<3 a) & 6 & 92 \\
\hline B.Madurell Sud & MS21A & Neolítico Medio II & Contenedor funerario & 1 SubAD/hembra (15 a) & 1 & 6 \\
\hline B.Madurell Sud & MS23 & Neolítico Medio II & Contenedor funerario & $1 \operatorname{SubAD}(9 \mathrm{a})$ & 1 & 2 \\
\hline B.Madurell Sud & MS28 & Neolítico Medio II & Contenedor funerario & 1 SubAD (4-6 a) & 2 & 2 \\
\hline B.Madurell Sud & MS62 & 4230-3950 cal BC & Tumba & 1 SubAD/hembra (14 a) & 1 & 2 \\
\hline B.Madurell Sud & MS65 & 3955-3770 cal BC & Contenedor funerario & $1 \mathrm{AD} / \mathrm{macho}$ & 1 & 3 \\
\hline B.Madurell Sud & MS67 & Neolítico Medio II & Tumba & 1 SubAD (infantil) & 2 & 5 \\
\hline B.Madurell Sud & MS69 & 4230-3975 cal BC & Tumba & $1 \mathrm{AD} /$ macho & 1 & 2 \\
\hline B.Madurell Sud & MS70 & Neolítico Medio II & Contenedor funerario & 1 SubAD (infantil) & 2 & 13 \\
\hline \multirow{2}{*}{ B.Madurell Sud } & \multirow{2}{*}{ MS78 } & \multirow{2}{*}{ 3940-3705 cal BC } & \multirow{2}{*}{ Contenedor funerario } & $1 \mathrm{AD} /$ macho & \multirow{2}{*}{8} & \multirow{2}{*}{105} \\
\hline & & & & 3 SubAD (5a/8-9a/7-8a) & & \\
\hline B.Madurell Sud & MS79 & Neolítico Medio II & Tumba & 1 subAD & 1 & 1 \\
\hline B.Madurell Ferrocarrils & MF10 & Neolítico Medio II & Tumba & $1 \mathrm{AD} /$ hembra & 1 & 3 \\
\hline B.Madurell Ferrocarrils & MF18 & 3940-3705 cal BC & Contenedor funerario & $2 \mathrm{AD} / \mathrm{machos}$ & 2 & 4 \\
\hline
\end{tabular}

Tabla 1: Información general de las estructuras funerarias de Bòbila Madurell con restos de bovino. Las dataciones fueron extraídas de Gibaja et al., 2017. Las edades en los humanos se clasifican: infantiles hasta los 3 años; Subadultos de 3-15 años y Adultos a partir de los 16 años (extraído de Martín Cólliga et al., 2017). / General information of the funerary structures of Bòbila Madurell with bovine remains. The radiocarbon data were extracted from Gibaja et al., 2017. The age of humans has been classified: Infants up to 3 years old; Sub-Adults from 3-15 years old; Adults from 16 years old (extracted from Martín Cólliga et al., 2017).

con cronología dilatadas para poder tener un espectro más amplio sobre la evolución del tamaño del bovino en el territorio estudiado. Es el caso de Can Roqueta en el Bronce Inicial (Albizuri, 2011), y del sector Ibero-ro- mano Can Feu, dentro de Bòbila Madurell, datado en el s. II BC (Albizuri y Folch, 2019).

El resumen de medidas utilizadas se puede consultar en las tablas 2, 3 y 4 .

\begin{tabular}{|c|c|c|c|c|c|c|c|c|c|c|}
\hline Yacimiento & Estructura & Período & Taxón & Sexo & Altura Cruz (cm) & GL & Bp & SD & Bd & BFd \\
\hline Gibijo (Álava) & GITx & Mesol. & Bos primigenius & & & $\mathbf{2 6 7}$ & & $\mathbf{5 2 , 0}$ & & $\mathbf{8 6 , 0}$ \\
\hline Gibijo (Álava) & Las Grajas II & Mesol. & Bos primigenius & M & & $\mathbf{2 3 6}$ & $\mathbf{7 8 , 0}$ & $\mathbf{4 5 , 0}$ & $\mathbf{7 6 , 0}$ & $\mathbf{8 0 , 0}$ \\
\hline Casserna S. Pau & & NM-I & Bos taurus & & 118,7 & $(190)$ & & & & \\
\hline Pujolet de Moja & 31 & NM-I & Bos taurus & H & 111 & 185 & 53,7 & 28,7 & & 54,5 \\
\hline Pujolet de Moja & 38c & NM-I & Bos taurus & H & 108,6 & 181 & 54,2 & 28,3 & & 56,8 \\
\hline Pou Nou 2 & 11 & NM-I & Bos taurus & & & $(189)$ & & 20,8 & & \\
\hline Pou Nou 2 & 17 & NM-I & Bos taurus & & & & 67,2 & & & \\
\hline Pou Nou 2 & 16 & NM-I & Bos sp. & & & & 74,8 & & & \\
\hline Pou Nou 3 & E-3 & NM-I & Bos sp. & & & & & & & $\mathbf{6 7 , 9}$ \\
\hline Can Roqueta & CRCRV255 & NM-I & Bos taurus & & 104,6 & 170 & & 33,6 & & 58,8 \\
\hline Bòbila Madurell & MS17 & NM-II & Bos taurus & & & & & & 49,9 & 58,3 \\
\hline Bòbila Madurell & MS78 & NM-II & Bos taurus & & & & & 36,9 & & 63,9 \\
\hline Bòbila Madurell & MS78 & NM-II & Bos taurus & & & & & & & \\
\hline Bòbila Madurell & MS78 & NM-II & Bos taurus & & & & & & 54,5 & 60,6 \\
\hline Bòbila Madurell & H1. G16 & NM-II & Bos taurus & & & & & & & 66,0 \\
\hline Bòbila Madurell & H1. H18 & NM-II & Bos taurus & & & & & & 50,7 \\
\hline
\end{tabular}




\begin{tabular}{|c|c|c|c|c|c|c|c|c|c|c|}
\hline Yacimiento & Estructura & Período & Taxón & Sexo & Altura Cruz $(\mathbf{c m})$ & GL & Bp & SD & Bd & BFd \\
\hline Bòbila Madurell & B12 & NM-II & Bos taurus & & & & & & & \\
\hline La Renke (Álava) & & NF & Bos taurus & & & & 54,0 & 29,0 & & \\
\hline La Renke (Álava) & & NF & Bos primigenius & & & & $\mathbf{6 7 , 5}$ & & & \\
\hline Can Roqueta & CRII459 & BI & Bos taurus & & 98,4 & 160 & & 23,8 & & 46,3 \\
\hline Can Roqueta & CRII348 & BI & Bos taurus & & 111 & 182 & & 28,3 & & 57,5 \\
\hline Can Roqueta & CRII505 & BI & Bos taurus & & 116,9 & 190 & & 27,9 & & 59,4 \\
\hline
\end{tabular}

Tabla 2: Medidas de los metacarpos (en mm). Bovinos domésticos y salvajes del norte de la Península lbérica: Mesolítico (Mesol.), Neolítico Medio I y II (NM-I y NM-II), Neolítico Final (NF), Bronce Inicial (BI). Entre paréntesis, medidas tomadas con dificultad debido al estado de deterioro del hueso. Abreviaturas de las medidas: GL: Iongitud máxima; Bp: anchura (máxima) de la epífisis proximal; SD: anchura mínima de la diáfisis; Bd: anchura (máxima) de la epífisis distal; BFd: anchura distal máxima. / Metacarpal measurements (in mm). Domestic and wild bovines from the north of the Iberian Peninsula: Mesolithic (Mesol.), Middle Neolithic I and II (NM-I and NM-II), Late Neolithic (NF), Early Bronze Age (BI). In brackets, measurements taken with difficulty due to the state of deterioration of the bone. Abbreviations of the measurements: GL: greatest length; Bp: (Greatest) breadth of the proximal end; SD: smallest breath of the diaphysis; Bd: (greatest) breadth of the distal end; BFd: breadth of the distal end.

\begin{tabular}{|c|c|c|c|c|c|c|}
\hline Yacimiento & Estructura & Período & Taxón & GLI & GLm & $\mathrm{Bd}$ \\
\hline Gibijo (Álava) & Las Grajas II & Mesol. & Bos primigenius & 86,0 & 79,0 & 59,0 \\
\hline Arenaza (Vizcaya) & & Mesol. & Bos primigenius & 76,0 & 71,0 & 55,0 \\
\hline Chaves (Huesca) & & NA & Bos primigenius & 81,5 & 78,0 & 52,0 \\
\hline Chaves (Huesca) & & NA & Bos taurus & 71,0 & & 44,5 \\
\hline Chaves (Huesca) & & NA & Bos taurus & 63,5 & & 40,0 \\
\hline Chaves (Huesca) & & NA & Bos taurus & 67,0 & & 40,5 \\
\hline Chaves (Huesca) & & NA & Bos taurus & 64,0 & & 40,0 \\
\hline El Mirador (Burgos) & & NA & Bos taurus & 59,6 & 59,6 & 36,0 \\
\hline Bòbila Madurell & MS1 & NM-II & Bos taurus & 60,9 & 55,3 & 38,1 \\
\hline Bòbila Madurell & MS17 & NM-II & Bos taurus & 61,0 & 55,9 & \\
\hline Bòbila Madurell & MS78 & NM-II & Bos taurus & 62,2 & 57,0 & 37,2 \\
\hline Bòbila Madurell & $\mathrm{B} 12$ & NM-II & Bos taurus & 63,5 & & \\
\hline Bòbila Madurell & MS19 & NM-II & Bos taurus & 63,3 & 58,0 & 38,6 \\
\hline Bòbila Madurell & $\mathrm{B} 12$ & NM-II & Bos taurus & 63,6 & & \\
\hline Bòbila Madurell & MS78 & NM-II & Bos taurus & 65,5 & 59,5 & 32,9 \\
\hline Bòbila Madurell & MS17 & NM-II & Bos taurus & 65,7 & 59,6 & \\
\hline Bòbila Madurell & MS17 & NM-II & Bos taurus & 68,0 & 61,3 & \\
\hline Bòbila Madurell & $\mathrm{B} 12$ & NM-II & Bos taurus & 63,5 & & \\
\hline Bòbila Madurell & B12 & NM-II & Bos taurus & 63,6 & & \\
\hline Arenaza (Vizcaya) & & $\mathrm{NF}$ & Bos taurus & 69,0 & & 45,0 \\
\hline La Renke (Álava) & & $\mathrm{NF}$ & Bos taurus & 70,5 & & 43,5 \\
\hline La Renke (Álava) & & $\mathrm{NF}$ & Bos taurus & 67,0 & & 43,5 \\
\hline Can Roqueta & CRII505 & $\mathrm{Bl}$ & Bos taurus & 64,0 & & 42,0 \\
\hline Can Feu-Bòbila M. & $\mathrm{C} 15$ & IB-R & Bos taurus & 58,5 & 51,9 & 36,6 \\
\hline Can Feu-Bòbila M. & $\mathrm{C} 15$ & IB-R & Bos taurus & 55,4 & 50,1 & 37,2 \\
\hline Can Feu-Bòbila M. & C15 & IB-R & Bos taurus & 57,9 & 51,9 & 37,2 \\
\hline
\end{tabular}

Tabla 3: Medidas de los astrágalos (en mm). Bovinos domésticos y salvajes del norte de la Península lbérica: Mesolítico (Mesol.), Neolítico Antiguo (NA), Neolítico Medio II (NM-II), Neolítico Final (NF), Bronce Inicial (BI), Íbero-romano (IB-R). Abreviaturas de las medidas: GLI: longitud máxima de la cara lateral; GLm: longitud máxima de la cara medial; Bd: anchura (máxima) distal. / Dimensions of the astragali (in $\mathrm{mm}$ ). Domestic and wild bovines from the north of the Iberian Peninsula: Mesolithic (Mesol.), Early Neolithic (AN), Middle Neolithic II (NM-II), Late Neolithic (NF), Early Bronze Age (BI), Ibero-Roman (IB-R), Abbreviations of the measurements: GLI: greatest length of the lateral half; GLm: greatest length of the medial half; Bd: (Greatest) breadth of the distal end.

Con el fin de analizar las estrategias de gestión y aprovechamiento del ganado bovino se han generado los perfiles de muerte de los sectores MS y MF de acuerdo con criterios de fusión ósea y erupción y desgaste dentales (Barone, 1969; Silver, 1969; Grant, 1982). El ciclo reproductivo del ganado bovino le permite criar a lo largo de todo el año, pero factores ambientales (nutrición y clima) y parámetros fisiológicos 


\begin{tabular}{|c|c|c|c|c|c|c|}
\hline Yacimiento & Estructura & Período & Taxón & GLI & GLm & $\mathrm{Bd}$ \\
\hline Bòbila Madurell & MS78 & NM-II & Bos taurus & Falange 1 & 48,9 & 24,9 \\
\hline Bòbila Madurell & MS78 & NM-II & Bos taurus & Falange 1 & 56,9 & 25,0 \\
\hline Bòbila Madurell & MS78 & NM-II & Bos taurus & Falange 1 & 56,7 & 27,2 \\
\hline Bòbila Madurell & MS78 & NM-II & Bos taurus & Falange 1 & 58,6 & 25,1 \\
\hline Bòbila Madurell & MS7 & NM-II & Bos taurus & Falange 1 & 57,4 & 26,3 \\
\hline Bòbila Madurell & MS7 & NM-II & Bos taurus & Falange 1 & 57,8 & 25,9 \\
\hline Bòbila Madurell & MS17 & NM-II & Bos taurus & Falange 1 & 59,2 & 26,8 \\
\hline Bòbila Madurell & $\mathrm{B} 12$ & NM-II & Bos taurus & Falange 1 & 57,7 & 31,3 \\
\hline Bòbila Madurell & $\mathrm{B} 12$ & $\mathrm{NM}-\mathrm{II}$ & Bos taurus & Falange 1 & 55,3 & 27,8 \\
\hline Bòbila Madurell & B12 & $\mathrm{NM}-\mathrm{II}$ & Bos taurus & Falange 1 & 51,2 & \\
\hline Bòbila Madurell & $\mathrm{B} 12$ & NM-II & Bos taurus & Falange 1 & & 27,8 \\
\hline La Draga & & NA & Bos taurus (Oxen) & Falange 1 Ant. & 52,5 & 32,6 \\
\hline La Draga & & NA & Bos taurus & Falange 1 Ant. & 59,0 & 27,2 \\
\hline La Draga & & NA & Bos taurus & Falange 1 Ant. & 64,2 & 30,2 \\
\hline La Draga & & NA & Bos taurus & Falange 1 Ant. & 62,1 & 27,9 \\
\hline La Draga & & NA & Bos taurus & Falange 1 Post. & 60,8 & 31,0 \\
\hline La Draga & & NA & Bos taurus & Falange 1 Post. & 56,5 & 27,7 \\
\hline La Draga & & NA & Bos taurus & Falange 1 & 57,6 & 27,5 \\
\hline La Draga & & NA & Bos taurus & Falange 1 & 58,2 & 27,1 \\
\hline La Draga & & NA & Bos primigenius & Falange 1 & 66,1 & 33,7 \\
\hline Chaves (Huesca) & & NA & Bos taurus & Falange 1 & 61,5 & 32,5 \\
\hline Chaves (Huesca) & & NA & Bos taurus & Falange 1 & 65,5 & 37,5 \\
\hline Chaves (Huesca) & & NA & Bos taurus & Falange 1 & 59,0 & 30,0 \\
\hline Chaves (Huesca) & & NA & Bos taurus & Falange 1 & 65,5 & 27,5 \\
\hline
\end{tabular}

Tabla 4: Medidas de las primeras falanges (en mm). Bovinos domésticos y salvajes del noreste de la Península lbérica: Neolítico Antiguo (NA), Neolítico Medio II (NM-II). Abreviatura de las medidas: GL: Iongitud máxima; Bp: anchura (máxima) de la epífisis proximal. / Measurements of the first phalanges (in $\mathrm{mm}$ ). Domestic and wild bovines from the northeastern Iberian Peninsula: Early Neolithic (AN), Middle Neolithic II (MN-II). Abbreviation of measurements: GL: greatest length; Bp: (Greatest) breadth of the proximal end.

pueden determinar la estación de nacimiento. En la Europa templada, los nacimientos del ganado bovino extensivo se producen entre finales de invierno e inicios de la primavera, cuando la hierba fresca es más abundante (Kamjan et al., 2020).

Para este trabajo hemos utilizado datos sobre la estacionalidad del ciclo reproductivo de las razas actuales ibéricas para establecer una clasificación por categorías de edades. El primer estro del bovino acostumbra a aparecer a partir de los 12 meses (hasta los 17 meses) según la precocidad de las razas, y este hecho corre parejo a la consecución de un peso óptimo (Homedes, 1967). En las razas menos precoces, más similares a las antiguas, el primer celo puede presentarse alrededor de los 20 meses y los nacimientos han de estimarse durante la primavera, coincidiendo con el aumento de pastos, de forma similar a las europeas en estado de semilibertad y a los datos de bovino neolítico europeo (Kamjan et al., 2020). El periodo de gestación es de 9.5 meses a lo que debe sumarse entre 4-6 meses de lactancia (hasta los 12 meses se combina la lactancia y el pasto).
Bajo estos conceptos actualistas podemos asignar la categoría de "adultos" a los animales que superaban los 2 años y que habían alcanzado un peso óptimo (normalmente hacia los 12-18 meses). Las hembras adultas que superan los 36 meses habrían podido criar una vez. Los animales entre los 12-24 meses se engloban en la categoría de "subadultos" que habría alcanzado el $50 \%$ del peso adulto total (se considera a los 5 años). Los situados entre los 6-12 meses compondrían el conjunto de "jóvenes" postlactantes en los que se puede incluir los animales en régimen de lactancia/pasto con un peso entre el 15 y el 35\% del adulto. Los inferiores a 6 meses se han considerado "infantiles" lactantes.

\section{RESULTADOS}

\subsection{Análisis osteométrico}

La muestra analizada presenta características morfométricas similares a la de otros bovinos domésticos neolíticos del noreste y norte peninsular. Por el contrario, se encuentran fuera del rango osteométrico de los uros peninsulares (Fig. 3, 4, 5 y 6). 


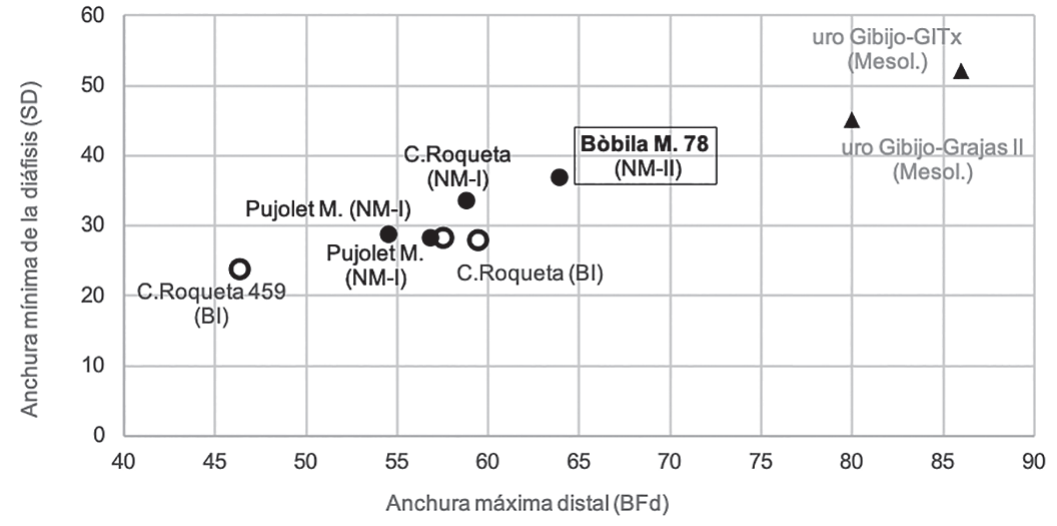

Fig.3. Medidas de los metacarpos. Bovino doméstico del noreste de la Península Ibérica: Neolítico Medio I (NM-I), Neolítico Medio II (NM-II), Bronce Inicial (BI). Uros mesolíticos (Mesol.) del norte de la Península Ibérica. / Metacarpal measurements. Domestic bovine from the northeastern Iberian Peninsula: Middle Neolithic I (NM-I), Middle Neolithic II (NM-II), Early Bronze Age (BI). Mesolithic (Mesol.) Uros from the north of the Iberian Peninsula.

Anchura máxima distal (BFd)

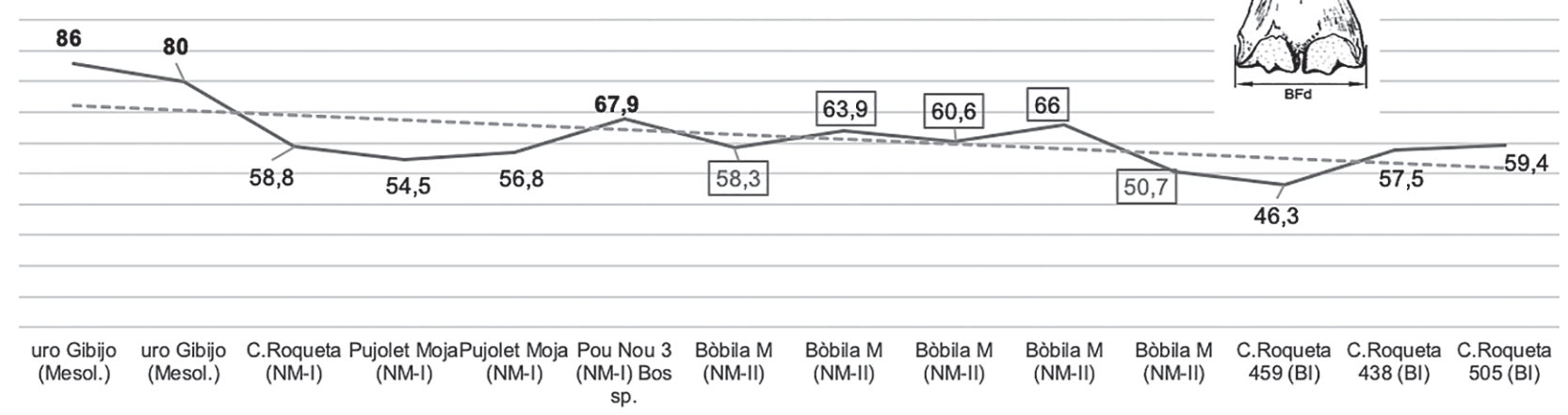

Fig.4. Medidas de la articulación distal de los metacarpos. Bovino doméstico y salvaje (en negrita) de la Península lbérica: Mesolítico (Mesol.), Neolítico Medio I (NM-I), Neolítico Medio II (NM-II), Bronce Inicial (BI). / Measurements in the distal end of the metacarpals. Domestic and wild bovine (in bold) from the Iberian Peninsula: Mesolithic (Mesol.), Middle Neolithic I (NM-I), Middle Neolithic II (NM-II), Early Bronze Age (BI).

La anchura distal y de la diáfisis de los metacarpos delimita la robustez de los animales y por tanto permite distinguir diferencias entre machos, hembras y castrados, y, por supuesto, entre domésticos y salvajes (Fig. $3,4)$. En los animales de la Bòbila Madurell, la anchura distal se sitúa entre 50 y $66 \mathrm{~mm}$ de forma bastante homogénea respecto a los del Neolítico Medio I del noreste (Fig. 4). A modo de hipótesis, los ejemplares que sobrepasan los $60 \mathrm{~mm}$ podrían considerarse dentro del grupo de machos domésticos y castrados, sobre todo en el caso del Bos sp. de Pou Nou 3 o el de Bòbila Madurell, ambos por encima de los 65 mm (Fig. 4). Por otro lado, remarcar que el rango de variabilidad de los uros hembras de Portugal se solapa con estos ejemplares más robustos (Fig. 5). Una tendencia a la reducción de los animales parece verificarse en el territorio de estudio a partir de los tres ejemplares del Bronce Inicial de Can Roqueta (Fig. 4, 5).

Rango de variabilidad en la anchura máxima distal (BFd) en los metacarpos

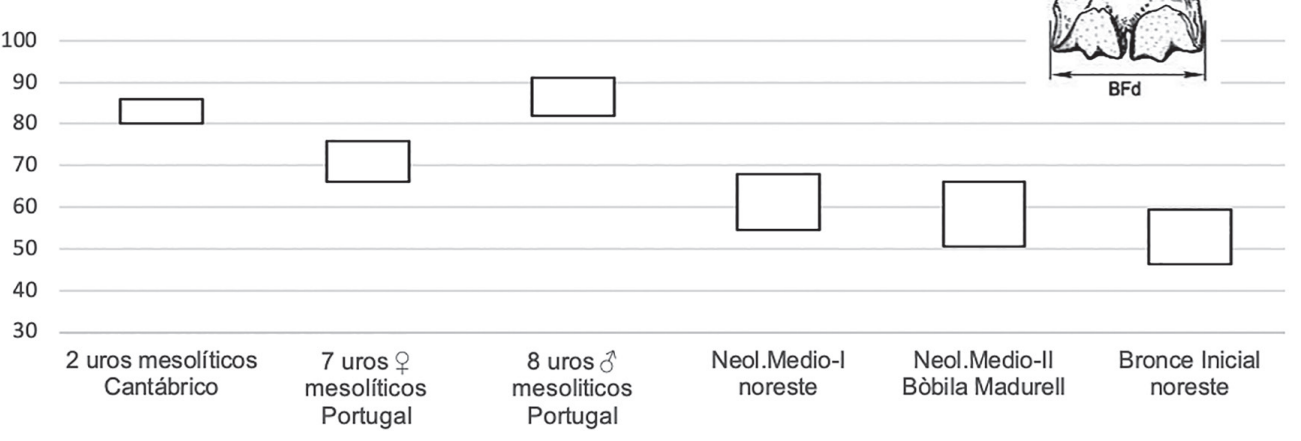

Fig.5. Rango de variabilidad en la anchura distal máxima (BFd) de los metacarpos. Bovino doméstico y salvaje de la Península Ibérica. / Range of variability in the maximum distal breath (BFd) of the metacarpals. Domestic and wild bovine of the Iberian Peninsula. 
El rango de variabilidad osteométrica en los astrágalos de la Bòbila Madurell también evidencia cierta homogeneidad respecto a los conjuntos del Neolítico peninsular, aunque relativamente distanciado de los ejemplares del Cantábrico, en general más robustos (Fig. 6). Esto contrasta con la disminución del tamaño de un animal del Bronce Inicial del vecino yacimiento de Can Roqueta y de los ejemplares ibero-romanos del sector Can Feu en Bòbila Madurell.

En el gráfico comparativo de las medidas de las primeras falanges de bovinos neolíticos, (Fig. 7) se observa una mayor homogeneidad en los individuos de la Bòbila Madurell que en los de los yacimientos del Neolítico Antiguo de Chaves y de La Draga, posiblemente porque reflejan mayor variabilidad sexual. En concreto, la Draga incluye un animal castrado, además de un uro (Helmer et al., 2018). Las medidas de las primeras falanges permiten observar una diferenciación más clara entre los bovinos de la Bòbila Madurell y los del Neolítico Antiguo de la Draga y de la Cueva de Chaves, estos últimos más robustos y grandes.

\subsection{Análisis de los perfiles de edad}

Ha sido posible estimar la edad de muerte de 28 individuos. Ésta se ha realizado en base al estado de erupción y desgaste en la dentición y, más concretamente, al cierre de las epífisis. Los perfiles de muerte reflejan un sacrificio centrado en animales que habían sobrepasado los 12-18 meses y habían llegado a su peso óptimo (78.6\%) (Fig. 8), recordando que la consecución del $50 \%$ del peso total se estima a partir de los 12-24 meses. Algunos de estos ejemplares, que sobrepasaban los 24-36 meses, pudieron llegar a reproducirse una vez como mínimo, según los periodos del ciclo reproductivo normal en razas rústicas actuales. Otros, en torno a los 24-30 meses, pudieron ser sacrificados en su peso óptimo sin reponer una cría al rebaño.

El grupo de individuos jóvenes y subadultos, entre los 7 y 18 meses, supondría un bajo porcentaje (21.4\%) respecto al de los adultos con mayor peso. Entre los adultos solo dos casos sobrepasaban los 4 años de vida. En los casos situados entre los 7-10 meses y 9-12 meses, se puede suponer un sacrificio de animales postlactantes.

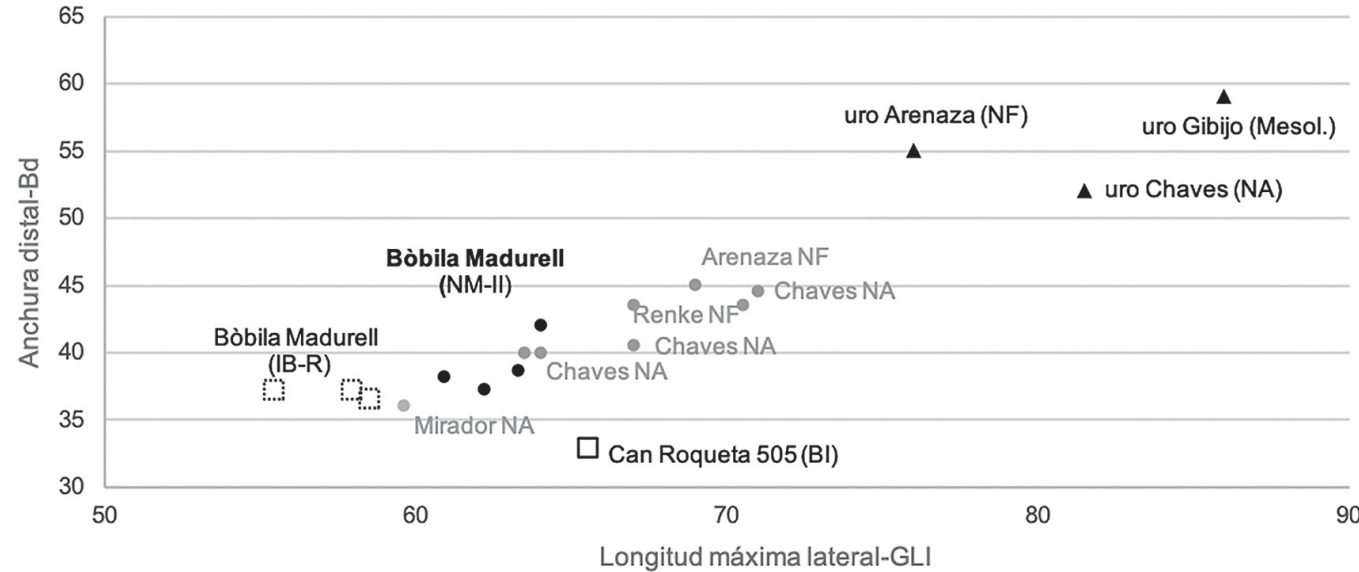

Fig.6. Medidas de los astrágalos. Bovinos domésticos y salvajes del norte de la Península Ibérica: Neolítico Antiguo (NA), Neolítico Medio II (NM-II), Neolítico Final (NF), Bronce Inicial (BI), Ibero-romano (IB-R). / Astragalus measurements. Domestic and wild bovines from the north of the Iberian Peninsula: Early Neolithic (AN), Middle Neolithic II (MN-II), Final Neolithic (NF), Early Bronze Age (IB), Ibe-

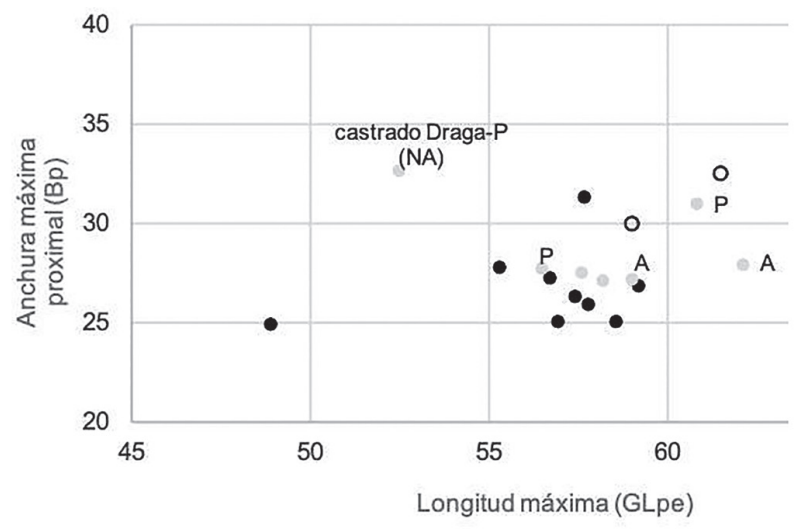

Fig.7. Medidas de las primeras falanges ( $A=$ anterior; $P=$ posterior $)$. Bòbila Madurell, Neolítico Medio II -NM-II- (negro); La Draga, Neolítico Antiguo -NA- (gris); Cueva de Chaves, Neolítico Antiguo -NA- (blanco). / Measurements of the first phalanges $(A=$ anterior; $P=$ posterior $)$. Bòbila Madurell, Middle Neolithic II -NM-II- (black); La Draga, Early Neolithic -NA- (gray); Cueva de Chaves, Early Neolithic -NA- (white).
Esos perfiles de edad son similares a los de Mas Duran, a excepción de la presencia de individuos infantiles (Fig. 9). Este hecho nos Ileva a plantear para los sectores funerarios un sacrificio centrado principalmente en animales con peso óptimo.

Las dos estructuras de los sectores funerarios en las que se registra un mayor número de individuos son la MS17 y MS78 y, por ello, se han utilizado como modelo teórico de un rebaño vivo simultáneo datado a inicios de la primera mitad del IV milenio cal BC. Ambas han proporcionado un total 14 ejemplares depositados en un mismo momento. El perfil de edades de muerte es similar en ellas, ya que predominan claramente los animales adultos sobre los situados alrededor del año. Ambas se diferencian del resto de las 18 fosas con restos humanos porque, en las últimas, no hay animales que sobrepasasen los 42 meses (Fig. 10) 


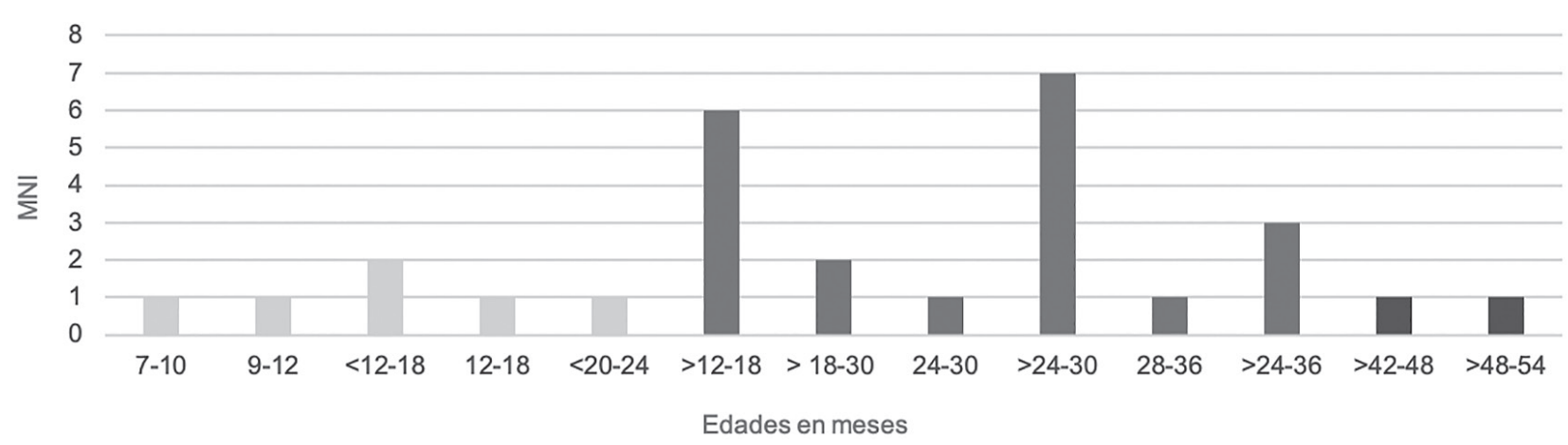

Fig.8. Bovino doméstico de la Bòbila Madurell: perfiles de edad de muerte. / Bòbila Madurell cattle: age-at-death profiles.

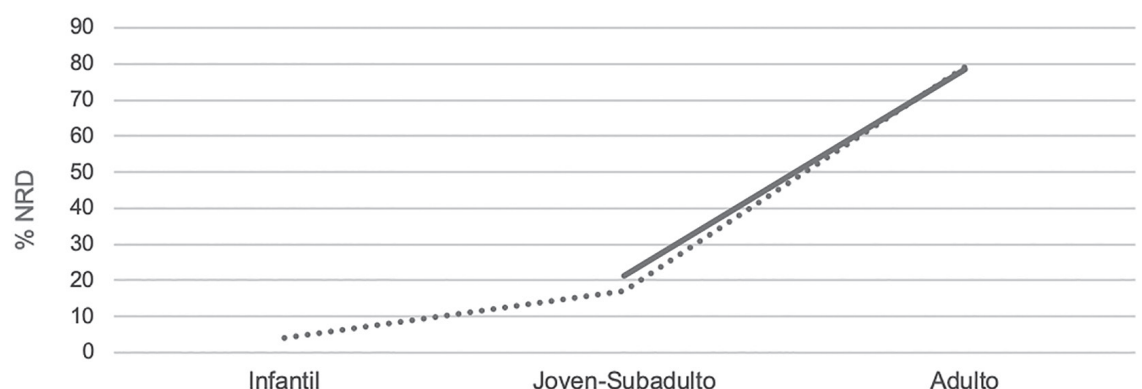

Madurell S-Madurell F (fosas funerarias $n=20$ ) $\square$ MS17 $\square$ MS78 $₫ 18$ estructuras funerarias (Edades en meses)

5

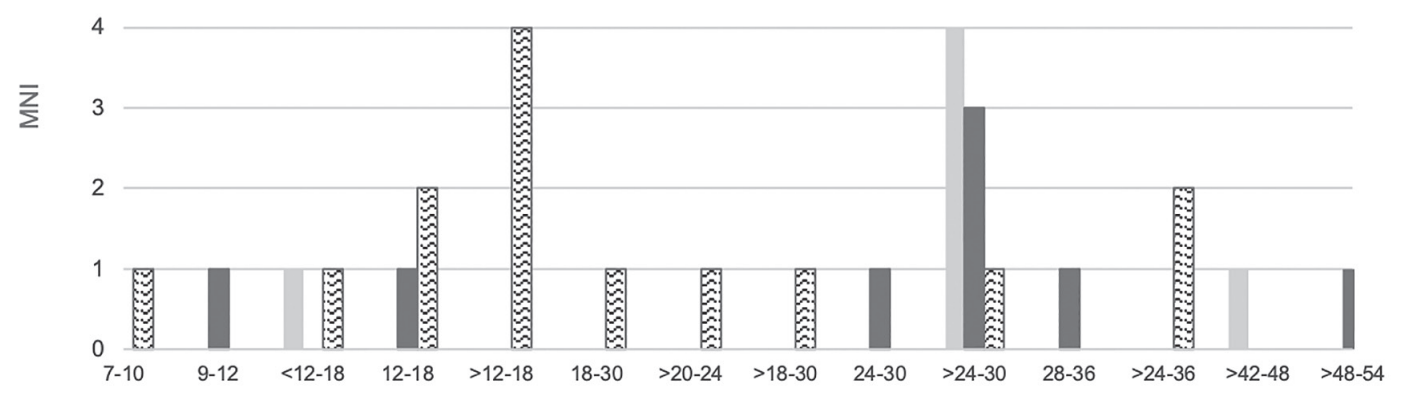

Fig.10. Perfiles de edad de los bovinos documentados en las estructuras MS17 y MS78 y en otras funerarias, edad en meses. / Age-at-death profiles of cattle documented in structures MS17 and MS78 and in other funerary structures (age in months).

\section{DISCUSIÓN}

El estudio osteométrico muestra que los bovinos, analizados en dos de los sectores funerarios de la Bòbila Madurell, se encuentran en líneas generales dentro de la variabilidad del ganado doméstico documentado en los yacimientos del Neolítico Antiguo y Neolítico Medio del noreste y norte de la Península Ibérica. Se excluye la presencia de uros en el conjunto analizado, por otro lado, documentados en Neolítico Medio en multitud de asentamientos europeos y peninsulares, normalmente de forma puntual. Algunos autores sostienen que su caza se produjo para preservar zonas de pasto (Davis y Sendim, 2020). En el noreste de la Península se han registrado algunos restos desde el Neolítico
Antiguo y Medio en la zona del Penedés (Nadal et al., 1999) y en el asentamiento lacustre de la Draga (Saña 2013; Helmer et al., 2018). Aunque en ocasiones los resultados osteométricos en Europa indican un solapamiento entre las hembras pequeñas de uro y los machos domésticos, hecho que puede provocar confusión en la lectura de resultados (Davis y Sendim, 2020). Por otro lado, recientes análisis morfogenéticos confirman la inclusión de uros en rebaños de ganado neolítico de Europa para su hibridación, ya desde el IV milenio BC (Schibler et al., 2015).

Las publicaciones que recogen información osteométrica de bovinos neolíticos son escasas, aunque los datos publicados en la mitad septentrional de la Pe- 
nínsula lbérica nos han permitido una comparación con la Bòbila Madurell. Los resultados indican una relativa homogeneidad en las proporciones de robustez del bovino doméstico en el noreste, desde el final del $\mathrm{V}$ milenio y a lo largo del VI cal BC, con una ligera tendencia a la reducción a partir del Neolítico Medio II (Fig. 5). En los yacimientos cercanos a la Bòbila Madurell esta tendencia parece más evidente a partir del Bronce Inicial en los casos de Can Roqueta, con animales que indican en general una variabilidad similar a los más gráciles del Neolítico Medio (Fig. 4). Sin embargo, los ibero-romanos de Can Feu, en la Bòbila Madurell, ya muestran una clara reducción del tamaño. La importante disminución del tamaño del bovino doméstico en Europa desde el Neolítico Antiguo se ha relacionado con una intensificación de la ganadería (Manning et al., 2015). A partir del Neolítico Final, esta reducción progresiva se atribuye a los cambios en las estrategias de la reproducción animal, ahora más ligada a subadultos reproductores (producirían terneros más pequeños) y a los cambios en la alimentación causados por la disponibilidad de pastos y las estrategias en el pastoreo (Manning et al., 2015).

En general, en los astrágalos del norte de la Península se aprecian diferencias respecto a los del noreste, observándose animales más robustos en la mitad norte. Este hecho pudo deberse a una adaptación a la temperatura en distintas zonas (Davis y Sendim, 2020).

Dentro de la relativa homogeneidad observada en el noreste, la variabilidad de las medidas de los metacarpos y falanges parece reflejar el dimorfismo sexual característico entre machos y hembras. En los metacarpos de Bòbila Madurell (Fig. 4) se distinguen cuatro individuos más robustos asimilables a machos y uno solo menor, bien diferenciado, que pudo corresponder a una hembra. Entre los más grandes hay un caso que pudo corresponder a un macho castrado.

La muestra faunística analizada en el conjunto de las estructuras funerarias y domésticas de la Bòbila Madurell indica, como hemos dicho, una explotación equilibrada de bovinos y ovicaprinos, y secundariamente, de cerdos. Los resultados en la estimación de edades del bovino en la necrópolis muestran un sacrificio centrado en subadultos y adultos con peso óptimo que pudo deberse a un aprovechamiento cárnico como objetivo prioritario. El análisis de los 14 ejemplares contemporáneos identificados en las estructuras MS78 (3940-3705 cal BC) y MS17 (3939-3681 cal BC) nos han permitido reducir el amplio marco cronológico de la Bòbila Madurell y ajustar el modelo teórico de la conformación del rebaño para un momento determinado (Fig. 10). La mitad de los animales sobrepasaba los 2 dos años y medio de edad, hecho que nos sitúa ante individuos en un peso óptimo que podrían haberse reproducido. Junto a los dos casos donde se ha podido asignar una edad precisa situada entre los 24 y 36 meses, parece reflejarse un sacrificio centrado en animales con un solo momento de cría y un destete entre los 4 y 6 meses. Esto implicaría una explotación centrada en conservar un número de- terminado de animales y en el aprovechamiento máximo cárnico. Sólo dos ejemplares que sobrepasaban los 4 años pudieron estar relacionados con la reserva de una pequeña proporción de individuos a la reproducción continuada del rebaño. Otros dos animales, a priori postlactantes, situados entre los 7 y 12 meses, pueden reflejar periodo de destete soportado por la ingesta de pasto, según datos procedentes de explotaciones actuales. En la misma línea, algunos estudios sobre la ganadería europea neolítica proponen que para el mantenimiento de la producción de leche en las madres se habrían mantenido vivos a los terneros después del período de lactancia, calculada en 3-4 meses, y que los picos de sacrificio entre los 6-12 meses, constituirían una indicación de sacrificio centrado en la obtención adicional de producción lechera por la prolongación del destete (Gillis et al., 2013). En este modelo teórico de gestión debemos incluir los infantiles identificados en las fosas de carácter doméstico del sector de Mas Duran (Fig. 9), ya que matizan la estrategia general y reflejan el sacrificio de lactantes.

En resumen, la cabaña bovina estuvo constituida por un número de cabezas importante considerando el grupo de 14 animales contemporáneos recuperados en las fosas MS17 y MS78. Estuvo gestionada de forma óptima para la reproducción constante del rebaño y el aprovechamiento cárnico y secundariamente lechero.

Los altos porcentajes de representación del bovino doméstico en las estructuras neolíticas, tanto funerarias como domésticas, de la Bòbila Madurell reflejan la creciente importancia que tuvo esta cabaña en la economía de estos grupos humanos. Esto fue seguramente debido a su alto rendimiento cárnico y lechero en comparación a los ovicaprinos y, por supuesto, a su potencial fuerza para las labores agrícolas. A pesar de que no hemos detectado evidencias claras de deformaciones patológicas por uso de los animales en el tiro y arrastre, no podemos descartar la utilización de estos animales en dichas labores, sobre todo teniendo en cuenta que estamos analizando una muestra sesgada por la selección humana para el ritual funerario. En realidad, la documentación directa o indirecta sobre el uso del bovino para el arado se remonta al Neolítico Antiguo en el territorio de estudio, en concreto en el asentamiento de la Draga (Tarrús et al., 2006). Estas evidencias podrían explicar una explotación ganadera cada vez más especializada en el vacuno dentro de los asentamientos con importante dedicación agrícola. En el sudeste de Francia las patologías en las primeras y segundas falanges indican un relativo aprovechamiento de los animales en el trabajo hasta el IV milenio BC, pero su función en las labores del campo y el transporte se incrementan a partir del Neolítico Final (Helmer et al., 2018).

\section{CONCLUSIONES}

Los depósitos animales en 20 estructuras de la necrópolis de la Bòbila Madurell, sectores Madurell Sud y 
Madurell Ferrocarrils, ponen de manifiesto un modelo mixto ganadero especializado en la cría de ganado vacuno y, de forma muy equilibrada, en la de los ovicaprinos, en el que los cerdos tendrían un papel secundario. Esta configuración faunística refleja, con leves variaciones, la analizada en estructuras domésticas y de habitación del sector Mas Duran y, por tanto, podemos asumir que el papel de los animales en la economía se trasladó a las practicas rituales relacionadas con las ceremonias funerarias.

En este modelo ganadero, el bovino doméstico está mejor representado dentro de estructuras con restos humanos asociados y los patrones de mortalidad reflejan una selección preferente de animales con peso óptimo, seguramente sacrificados para la celebración de banquetes comunales.

En general, los perfiles de edad en estructuras domésticas y funerarias indican que, en la Bòbila Madurell, el bovino se crio básicamente para el aprovechamiento cárnico. Aunque algunos animales se destinaron a la reproducción y también al aprovechamiento lechero de forma secundaria. En este sentido, el mantenimiento de añojos postlactantes pudo favorecer la continuidad de producción de leche en las madres para ser aprovechada por los humanos.

Los datos osteométricos reflejan un rebaño de bovinos de características morfológicas similares a los del Neolítico Medio en el noreste peninsular. Dentro de la variabilidad observada, se incluyen animales con índices de robustez variable asimilables a la hembras y machos y no se identifican bovinos salvajes.

\section{AGRADECIMIENTOS}

Este trabajo se ha realizado bajo el soporte de la beca Juan de la Cierva-Formación P. Martín (FJCl2016-29045) y de varios proyectos nacionales. Ministerio de Economía, Industria y Competividad: HAR2017-87695-P, HAR2016-75201-P, HAR201123149 and HAR2017-87695-P. Generalitat de Catalunya: SGR2017-00011.

\section{BIBLIOGRAFÍA}

Albizuri, S., Nadal, J., 1993. Resultats de l'estudi arqueozoològic del jaciment Caserna de Sant Pau (Barcelona). Pyrenae 24, 79-85.

Albizuri, S., 2011. La ofrenda animal durante el Bronce Inicial en Can roqueta II (Sabadell, Vallès Occidental). Arqueozoología del ritual funerario. Tesis doctoral, Departament d'Historia i Historia de l'Art, Universitat de Girona, Girona.

Albizuri, S., Folch, J., 2019. Los depósitos faunísticos de Can Feu (Sant Quirze del Vallès, Barcelona). Un reflejo del imaginario en el marco del final de la cultura ibérica. Pyrenae 50 (2), 7-28.

Albizuri, S., Nadal J, Martín, P., Gibaja, J.F., Martín Cólliga, A., Esteve, X., Oms, X., Martí, M., Pou, R., López-Onaindia, D.,
Subirà, M.E., 2019. Dogs in funerary contexts during the Middle Neolithic in the northeastern Iberian Peninsula (5th-early 4th millennium BCE). Journal Archaeological Science Reports 24, 198-207.

Altuna, J., 1974. Hallazgo de un uro (Bos primigenius Boj) en la sierra de Gibijo (Álava). Estudio de su esqueleto y de la fauna asociada al mismo. Munibe 26, 27-51.

Altuna, J., 1980. Historia de la domesticación en el País Vasco desde sus orígenes hasta la romanización. Munibe 32, 9-163.

Altuna, J., Mariezcurrena, C., 2001. La cabaña ganadera del yacimiento de La Renke (Alava, País Vasco). Munibe ANtropologia-Arkeologia 53, 75-86.

Altuna, J., Mariezcurrena, C., 2009. Tipos de cabañas ganaderas durante el Neolítico del País Vasco y zonas próximas. Archaeofauna 18, 137-157.

Antolin, F., Jacomet, S., Buxó, R., 2015. The hard knock life. Archaeobotanical data on farming practices during the Neolithic (5400e2300 cal BC) in the NE of the Iberian Peninsula. Journal of Archaeological Science 6, 90-104.

Barone, R., 1969. Anatomie compare des Mammifères domestiques. Tome 1. Vigot Frères Éditeurs, París.

Castaños, P., 1984. Estudio de los macromamíferos de la Cueva de Santimamiñe. Kobie 14, 235-318.

Castaños, P., 2004. Estudio arqueozoológico de los macromamíferos del Neolítico de la Cueva de Chaves (Huesca). Saldvie 4, 125-17.

Claro, D., 2018. Algunos aspectos del manejo de praderas con ovinos y vacunos. Disponible en: www.goldensheep.cl

Davis, S.J.M., Mataloto, R., 2012. Animal remains from Chalcolithic São Pedro (Redondo, Alentejo) evidence for a crisis in the Mesolithic. Revista portuguesa de Arqueologia 15(1), 47-85.

Davis, S.J.M., Sendim, A., 2020. Measurements of bones of seven female Barrosãs and one male Barrosão (Bos taurus L. 1758): a baseline for zooarchaeologists with notes on the evolution of Portuguese aurochsen and cattle. Sagvntvm-Extra 21, Homenaje al Profesor Manuel Pérez Ripoll, 61-86.

Díaz-Zorita, M., Subirá, M.E., Fontanals-Coll, M., Knudson, K.J., Alonzi, E., Bolhofner, K., Morell, B., Remolins, G., Roig, J., Martín, A., González Marcén, P., Plasencia, J., Coll, J.M., Gibaja, J.F. 2021. Neolithic networking and mobility during the 5 th and 4th millennia BC in north-eastern Iberia. Journal of Archaeological Science 125, 105272

Driesch, A. von den, 1976. A guide to the measurement of animal bones from archaeological sites, Peabody Museum Bulletin 1, Cambridge Mass., Harvard University, Cambridge.

Fontanals-Coll, M., Subirà, M.E., Díaz-Zorita, M., Duboscq, S., Gibaja, J.F., 2015. Investigating palaeodietary and social differences between two differentiated sectors of a Neolithic community, La Bòbila Madurell-Can Gambús (north-east Iberian Peninsula). Journal of Archaeological Science. Reports 3, 160-170.

Gibaja, J., Morell, B., Álvarez, J., Duboscq, S., Masclans, A., Remolins, G., Roig, J., Martín, A., González, P., Plasencia, J., Coll, J.M., Subirà, M., 2017. The Chronology of the Neolithic Necropolis Bòbila Maduell-Can Gambús in the Northeast Iberian Peninsula: Dating the Pit Burials Cultural Horizon and Long-Range Raw Material Exchange Networks. Radiocarbon 59(6), 1713-1736. 
Gillis, R., Bréhard, S., Balaşescu, A., Ughetto-Monfrin, J., Popovici, D., Vigne, J.D., Balasse, M., 2013. Sophisticated cattle dairy husbandry at Borduşani-Popina (Romania, fifth millennium BC): the evidence from complementary analysis of mortality profiles and stable isotopes. World Archaeology 45(3), 447-472.

Grant, A., 1982. The use tooth wear as guide to the age of domestic ungulates. In: Wilson B, Grigson C, Payne S (eds) Ageing and sexing animal bones from archaeological sites. BAR British series, Vol. 109, 91-109. British Archaeological Reports, Oxford.

Helmer, D., Blaise, E., Gourichon, L., Saña-Seguí, M., 2018. Using cattle for traction and transport during the Neolithic period Contribution of the study of the first and second phalanxes. Bulletin de la Société Préhistorique Française 115(1), 71-98.

Homedes, J., 1967. Ganado vacuno. Ganado caballar, asnal y mular. Sintes, Barcelona.

Kamjan, S., Gillis, R.E., C, Akırlar C., Raemaekers, D.C.M., 2020. Specialized cattle farming in the Neolithic Rhine-Meuse Delta: Results from zooarchaeological and stable isotope $(\delta 180, \delta 13 \mathrm{C}, \delta 15 \mathrm{~N})$ analyses. PLoS ONE 15(10), e0240464.

Laurino, M., 2006. Los uros de la sima Txiripi (Gibijo, Álava). Instituto Alavés de la Naturaleza, Departamento Paleontología del Cuaternario. Memoria 2006, 2-49.

Manning, K., Timpson, A., Shennan, S., Crema, E., 2015. Size Reduction in Early European Domestic Cattle Relates to Intensification of Neolithic Herding Strategies. PLoS ONE 10(12), e0141873.

Martín, P., 2015. Caracterización zooarqueológica de las cuevas redil en la Prehistoria de la Meseta Norte: el caso de El Mirador (Sierra de Atapuerca, Burgos). Tesis doctoral. Universitat Rovira i Virgili, Tarragona.

Martín, P., Albizuri, S., Martín Cólliga, A., Gibaja, J.F., 2019. Offerings, feasting, and psychopomps in the north-east of the Iberian Peninsula: the role of animals in the Bòbila MadureII (Sant Quirze del Vallès, Barcelona) funerary ritual (late fifth millennium-early fourth millennium cal BC). Archaeological Anthropological Sciences 11, 6615-6637.

Martín Cólliga, A., Blanch, R.M., Albizuri, S., Alaminos, A., Mercadal, O., Vives, E., Lázaro, P., Bosch, J., Colomer, S., Miret, J., Enrich, R., Aliaga, S., 2017. El paraje de Bòbila Madurell (Sant Quirze del Vallès, Vallès Occidental, Barcelona). In: Gibaja, J.F., Subirá, M.E., Martín, A., Mozota, M., Roig, J., (Coords.), Mirando a la Muerte: Las prácticas funerarias durante el neolítico en el noreste peninsular, 103-274. E-ditArx-Publicaciones Digitales. Colección Akademos, vol. I, Barcelona.

Nadal, J., Senabre, M. R., Mestres, J., Cebrià, A., 1999. Evolución del aprovechamiento de los recursos faunísticos durante el Neolítico en la comarca del l'Alt Penedès (Barcelona). II Congrés del Neolitic a la Península Ibérica. Saguntum Extra 2, 85-93.

Navarrete, V., Tornero, C., Balasse, M., Saña, M., 2019. Food management of early introduced caprine and bovine herds in the early Neolithic site of La Draga (Banyoles): An isotopic approach. International Journal Osteoarchaeology 29(6), 986-998.

Plasencia, F.J., 2016. Bòbila Madurell-Mas Duran: Formas de vida en el Neolítico medio y final del nordeste peninsular. Tesis doctoral, Universitat Autònoma de Barcelona, Bellaterra.

Saña, M., 1998. Arqueozoologia i faunes neolítiques a Catalunya. Problemàtica plantejada entorn a la dinàmica del procés de domesticació animal. Cypsela 12, 99-110.
Saña, M., 2013. Domestication of animals in the Iberian Peninsula. In: College, S., Conolly, J., Dobney, K., Manning, K., Shennan, S. (Eds), The origins and spread of domestic animals in Southwest Asia and Europe, 195-220. Left Coast Press California, California.

Saña, M., Antolín, F., Alcántara, R., Sierra, A., Tornero, C., 2020 Interpretating domesticates: earliest farming experiences in the Iberian Peninsula. In: Gron, K.J., Sorensen, L., RowleyConwy, P. (Eds.), Farmers at the Frontier: A Pan European Perspective on Neolithisation, 161-176. Oxbow Books, Oxford and Philadelphia.

Silver, I. A., 1969. The ageing of domestic animals. In: Brothwell, D.R., Higgs, E.S. (Eds.) Science in archaeology: a comprehensive survey of progress and research, 283-302. Thames and Hudson, London.

Schibler, J., Elsner, J., Schlumbaum, A., 2015. Incorporation of aurochs into a cattle herd in Neolithic Europe: single event or breeding? Science Reports 4, 5798 https://doi.org/10.1038/ srep05798.

Tarrús, J., Saña, M., Chinchilla, J., Bosch, A. 2006. La Draga (Banyoles, Catalogne): traction animale à la fin du Vlè millénaire? In: Pétrequin, P., Arbogast, R.M., Pétrequin, A.M., van Willigen, S., Bailly, M. (Eds.), Premiers chariots, premiers araires: La diffusion de la traction animale en Europe pendant les IVè et Illè millénaires avant notre ère, 25-30. CRA-Monographies 29, CNRS Editions,

Terrats, N., Oliva, M., Majó, T. Clop, X., Palomo, A., Albizuri, S., en prensa. Estructura singular adscrita al Neolítico antiguo postcardial del yacimiento de Can Roqueta (Sabadell/Barberà del Vallès, Barcelona): CRCRV255, de uso comunal a espacio funerario. Los cambios económicos y sus implicaciones sociales durante el Neolítico de la Península Ibérica. VI Congreso de Neolítico de la Península Ibérica, Granada 2016. 
